\title{
VRAM flap for locally advanced breast cancer
}

\author{
René Aloisio da Costa Vieira ${ }^{1,2,3 *} \mathbb{0}$, Raphael Luiz Haikel ${ }^{4} \mathbb{B}$, \\ Luciano Ipólito Branquinho ${ }^{\mathbb{C}}$, Idam de Oliveira-Junior ${ }^{1,4}$ (])
}

\section{ABSTRACT}

The authors presented a case of a patient with locally advanced breast cancer, with mammary and axillary localization, initially considered non-resectable, with good response after neoadjuvant chemotherapy. Due to the location of the lesion and the need for extensive resection, radical mastectomy was performed, associated with reconstruction with myocutaneous flap of the vertical rectus abdominis muscle. Different therapeutic options, the reasons that determine this choice, and local long-term control were discussed.

KEYWORDS: breast neoplasms; myocutaneous flap; surgical flaps; neoadjuvant therapy.

\section{INTRODUCTION}

Vertical Rectus Abdominis Myocutaneous (VRAM) is a versatile flap ${ }^{1}$, generally used in pelvic reconstruction ${ }^{2}$ and, to a lesser extent, in the reconstruction of the chest wall after extensive resection in locally advanced breast carcinoma. It has a lower rate of necrosis compared to the Transverse Actus Abdominal Muscle Flap (TRAM), but it is associated with the presence of visible abdominal incision ${ }^{1,3}$, with a small cosmetic input ${ }^{4}$.

In the case of reconstruction of defects after mastectomy in locally advanced tumors, with the need to use myocutaneous flaps, the latissimus dorsi flap is the option ${ }^{5}$. However, there is space for the use of the abdominal external oblique muscle flap ${ }^{6}$, TRAM or VRAM 7 . A case in which VRAM was used was presented here, along with a discussion on the factors related to its choice and results.

\section{CASE REPORT}

A 63-year-old patient was admitted with a palpable complaint in her right breast six months ago. Upon examination, an ulcerated tumor mass with a foul odor was noted, measuring $15 \times 13 \mathrm{~cm}$, occupying external quadrants of the right breast, with extension to the axillary and dorsal regions (Figure 1A). In the right axillary region, lymph node conglomerate adhered to deep planes, cT4b cN2 M0, was palpated. Core biopsy was performed with anatomopathological (AP) analysis, identifying invasive ductal carcinoma, histological grade 3. Immunohistochemical study found a triple negative tumor. The patient underwent neoadjuvant chemotherapy (AC-T), with disappearance of ulceration, stability of the mammary lesion and satellite skin lesions, compromising the axillary and dorsal regions (Figures 1B and 1C). Subsequently, surgical treatment was performed using the Madden modified radical mastectomy technique (Figure 1D) with rotation of VRAM to close the defect in the chest wall (Figure 2), with good postoperative evolution (Figure 3). The AP analysis of the surgical specimen found metaplasic infiltrative carcinoma of the adenosquamous type, histological grade 3 , measuring $8 \mathrm{~cm}$ in the longest axis, with cutaneous involvement, free surgical margins and 0/12 axillary lymph nodes compromised by neoplasia. Adjuvance was performed with radiotherapy (plastron + axilla + supraclavicular fossa - 28 X 180 cGY). During the follow-up, 14 months after the end of treatment, the disease progressed with distant disease (lung) and, later, bone and plastron. Local recurrence (plastron) and death occurred at 37 months and 44 months after surgical treatment, respectively.

\section{DISCUSSION}

In choosing the flap to close the defect after mastectomy, several factors were involved: the surgeon's experience, the size of the defect, training in microsurgical techniques, and the potential complications involved. In general, the microsurgical and

1Postgraduate Program in Tocogynecology, School of Medicine of Botucatu - Botucatu (SP), Brazil.

${ }^{2}$ Postgraduate Program in Oncology, Hospital de Câncer de Barretos - Barretos (SP), Brazil.

${ }^{3}$ Department of Surgery, Mastology Division, Hospital de Câncer de Muriaé - Muriaé (MG), Brazil.

${ }^{4}$ Department of Mastology and Breast Reconstruction, Hospital de Câncer de Barretos - Barretos (SP), Brazil.

*Corresponding author: reneacv@terra.com.br

Conflict of interests: nothing to declare.

Received on: 12/24/2020. Accepted on: 03/03/2021 
myocutaneous flaps allow the closure of areas superior to the fasciocutaneous or dermo-fat flaps, except for the ipsilateral thoracoabdominal dermofat (ITADE) flap, which, despite covering an extensive area, is associated with a higher rate of complication and cutaneous necrosis, being the necrosis greater than $4.3 \%$ and smaller than $34.7 \%^{6,8,9}$.
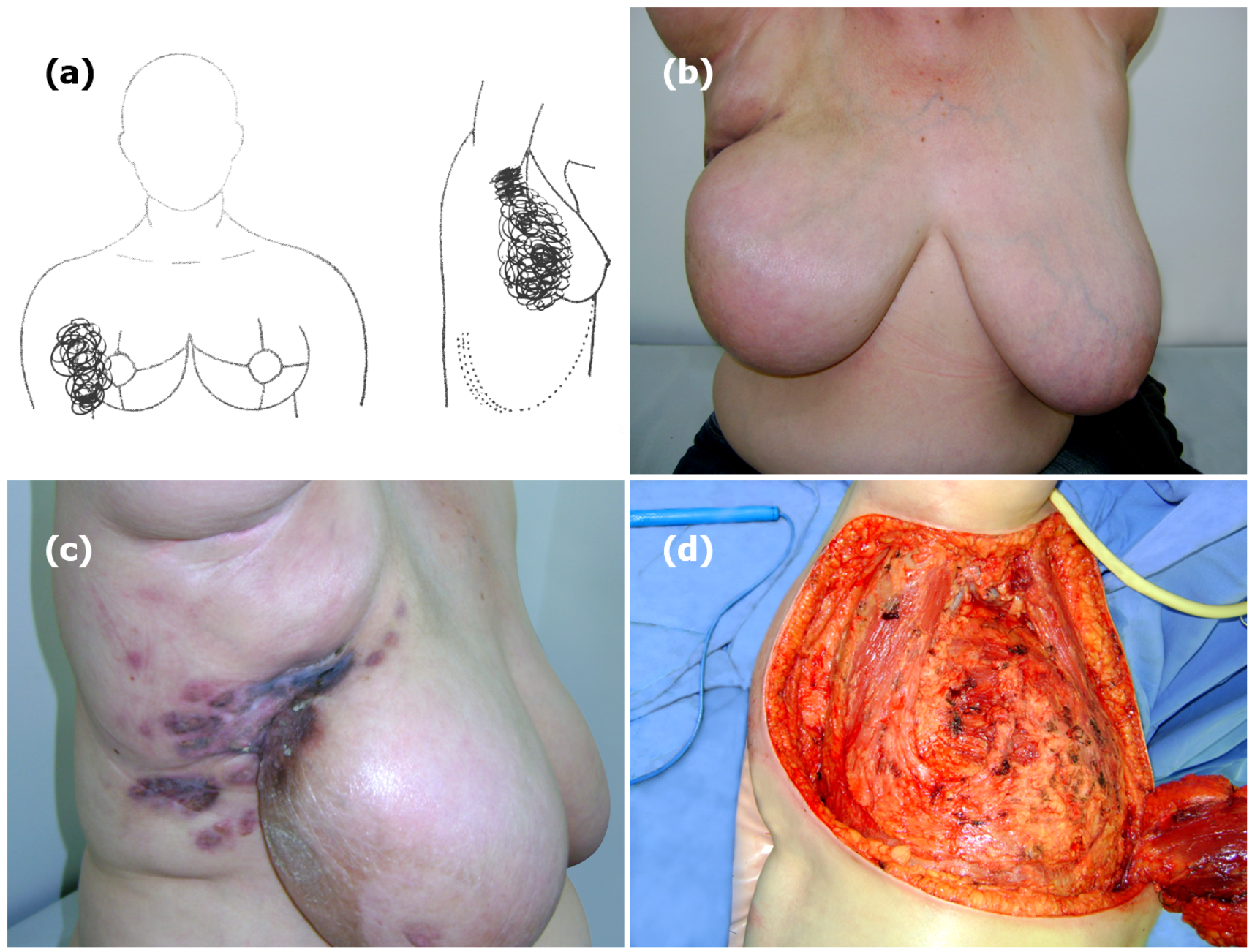

Figure 1. (A) Schematic representation prior to treatment; (B) control after neoadjuvant chemotherapy; (C) resection area; (D) resected area.
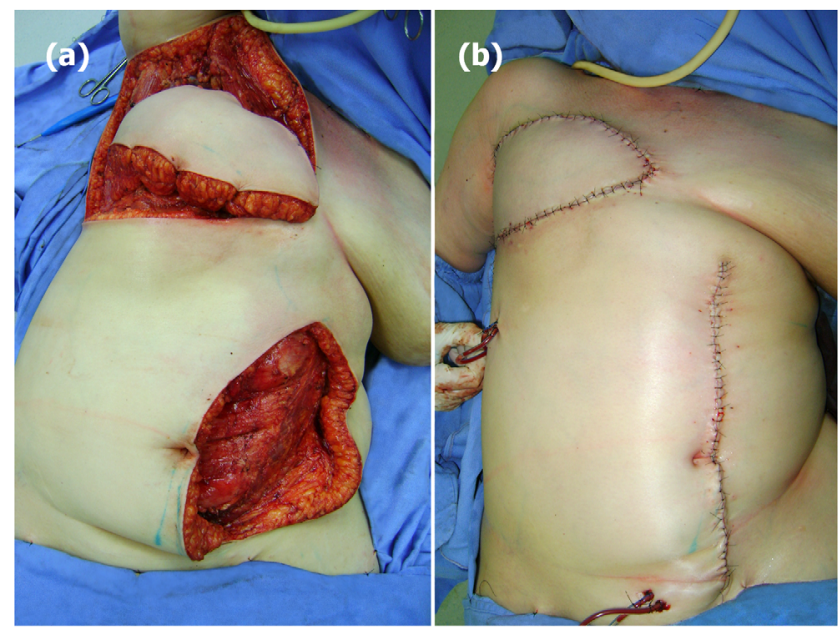

Figure 2. Vertical rectus abdominis flap. (A) Fabrication of the flap and transposition to the axillary region. Observe the use of zone I of the flap only. (B) Surgical result.
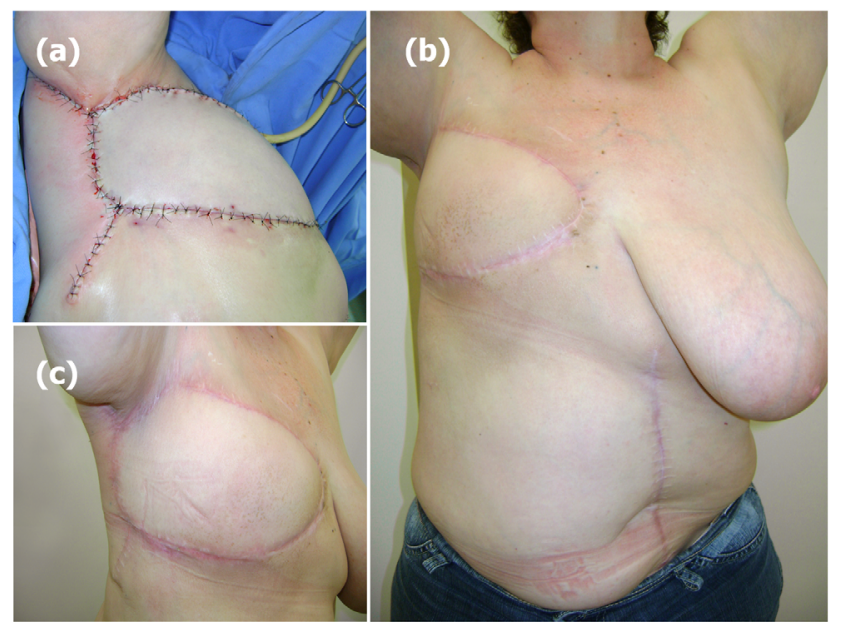

Figure 3. Vertical rectus abdominis flap: flap coverage area, with local healing and final result. (A) Intra-operative; (B and $C$ ) postoperative. 
It is known that fewservices have professionals qualified in microsurgical techniques, and the breast surgeon must have knowledge of the different reconstruction possibilities and their strengths and weaknesses, allowing the best choice of the myocutaneous flaps to be used. The latissimus dorsal flap is the one of choice. Despite disadvantages such as the incision on the back and the limitation of the skin donor area for very extensive defects ${ }^{5}$, it is the flap with a low rate of surgical complication and greater ease of execution.

The flap of the oblique abdominal muscle, little found in the literature, does not determine important fragility of the abdominal wall and is associated with an extensive scar, although it has a higher necrosis rate (less than $10 \%)^{10}$. The modification of the myocutaneous flap of the abdominal oblique, despite allowing coverage of an upper area, is associated with a high rate of necrosis $(70.6 \%)^{6}$, representing a good option for use in extreme cases.

VRAM, in turn, is a versatile flap, associated with a low rate of complications, but it generates fragility in the abdominal wall, as well as the presence of a vertical $\operatorname{scar}^{7,11}$, with less necrosis compared to TRAM ${ }^{12}$.

In the present case, the reconstruction was performed by mastologists and oncologic surgeons with knowledge of different flaps. The tumor was found in the breast and in the lateral region of the chest, which influenced the choice of the flap. The resection of an extensive lateral chest area, determined by tumor involvement, reduced the donor area of the latissimus dorsi, limiting the choice of this flap. Thus, the contralateral rectus abdominis muscle was considered as a choice, facilitated by the patient's body mass index and the availability of adipose tissue. In its manufacture, only the irrigation zone $\mathrm{I}^{3}$ was used, with a good donor area for coverage. In extreme cases, however, the skin donor area can be enlarged, with increased flap size and greater coverage, using tissue from zones II and $\mathrm{III}^{13}$.

The patient evolved well, and the surgery associated with the reconstruction allowed local control of the disease for 37 months, which positively influenced the quality of life ${ }^{2}$.

\section{CONCLUSION}

VRAM is an excellent flap that allows coverage of large skin defects in the chest wall. It constitutes yet another option to be considered after resection of locally advanced breast tumors.

\section{AUTHORS' CONTRIBUTION}

R.A.C.V: Conceptualization, formal analysis, investigation, methodology, project administration, supervision, writing — original draft, writing - review \& editing.

R.L.H.: Conceptualization, formal analysis, writing - review \& editing.

L.I.B.: Data curation, writing - review \& editing.

I.O.-J.: Investigation, methodology, supervision, writing - original draft, writing - review \& editing.

\section{REFERENCES}

1. Daigeler A, Simidjiiska-Belyaeva M, Drücke D, Goertz O, Hirsch T, Soimaru C, et al. The versatility of the pedicled vertical rectus abdominis myocutaneous flap in oncologic patients. Langenbecks Arch Surg. 2011;396(8):1271-9. https:// doi.org/10.1007/s00423-011-0823-6

2. O’Dowd V, Burke JP, Condon E, Waldron D, Ajmal N, Deasy J, et al. Vertical rectus abdominis myocutaneous flap and quality of life following abdominoperineal excision for rectal cancer: a multi-institutional study. Tech Coloproctol. 2014;18(10):901-6. https://doi.org/10.1007/s10151-014-1156-6

3. Kotti B. Optimizing the pedicled rectus abdominis flap: revised designs and vascular classification for safer procedures. Aesthetic Plast Surg. 2014;38(2):387-94.https://doi.org/10.1007/ s00266-014-0273-y

4. Fujiwara M, Nakamura Y, Sano A, Nakayama E, Nagasawa M, Shindo T. Delayed vertical rectus abdominis myocutaneous flap for anterior chest wall reconstruction. Aesthetic Plast Surg. 2006;30(1):120-4. https://doi.org/10.1007/s00266-005-0145-6

5. Munhoz AM, Montag E, Arruda E, Okada A, Brasil JA, Gemperli $\mathrm{R}$, et al. Immediate locally advanced breast cancer and chest wall reconstruction: surgical planning and reconstruction strategies with extendedV-Ylatissimusdorsimyocutaneousflap.PlastReconstrSurg. 2011;127(6):2186-97.https://doi.org/10.1097/prs.0b013e318213a038
6. Costa Vieira RA, Oliveira-Junior I, Branquinho LI, Haikel RL, Ching AW. Modified External Oblique Myocutaneous Flap for Repair of Postmastectomy Defects in Locally Advanced Breast Tumors: A Cohort Series Associated with a Systematic Review of Literature. Ann Surg Oncol. 2020. https://doi.org/10.1245/ s10434-020-09205-y

7. Mir M, Shahdhar M, Ganaie K, Syed Q. Oncological safety of immediate rectus abdominis myocutaneous breast reconstruction in patients with locally advanced disease (stage IIb and III). South Asian J Cancer. 2013;2(4):239-42. https://doi.org/10.4103/2278-330x.119921

8. Vieira R, Silva KMT, Oliveira-Junior I, Lima MA. ITADE flap after mastectomy for locally advanced breast cancer: A good choice for mid-sized defects of the chest wall, based on a systematic review of thoracoabdominal flaps. J Surg Oncol. 2017;115(8):949-58. https://doi.org/10.1002/ jso. 24619

9. Vieira RAC, Boni R, Silva VD. Reply: ITADE flap after mastectomy for locally advanced breast cancer: A good choice for mid-sized defects of the chest wall based on a systematic review of thoracoabdominal flaps. J Surg Oncol. 2019;119(8):1182-3. https://doi.org/10.1002/ jso. 25436 
10. Lee S, Jung Y, Bae Y. Immediate chest wall reconstruction using an external oblique myocutaneous flap for large skin defects after mastectomy in advanced or recurrent breast cancer patients: A single center experience. J Surg Oncol. 2018;117(2):124-9. https://doi.org/10.1002/ jso. 24830

11. Bassiouny MM, Maamoun SI, El-Shazly Sel D, Youssef OZ. TRAM flap for immediate post mastectomy reconstruction: comparison between pedicled and free transfer. J Egypt Natl Canc Inst. 2005;17(4):231-8.
12. Behnam AB, Nguyen D, Moran SL, Serletti JM. TRAM flap breast reconstruction for patients with advanced breast disease. Ann Plast Surg. 2003;50(6):567-71. https://doi. org/10.1097/01.sap.0000069075.27321.bc

13. Lin YN, Ou-Yang F, Hsieh MC, Lee SS, Huang SH, Chuang CH, et al. Use of Extended Pedicled Transverse Rectus Abdominis Myocutaneous Flap for Extensive Chest Wall Defect Reconstruction After Mastectomy for Locally Advanced Breast Cancer. Ann Plast Surg. 2020;84(1S Suppl. 1):S34-S39. https://doi.org/10.1097/sap.0000000000002188 